Instituto Internacional de Investigación y Desarrollo Tecnológico Educativo INDTEC, C.A.

DOI: https://doi.org/10.29394/Scientific.issn.2542-2987.2018.3.10.15.278-289

OAI-PMH: http://www.indteca.com/ojs/index.php/Revista Scientific/oai

Ensayo Original / Original Essay

\title{
Transdisciplinariedad: Una Mirada desde la Educación Universitaria
}

Autora: María Asunción Socorro

Universidad Politécnica Territorial del estado Mérida "Kléber Ramírez", UPTMKR

susysocorro@gmail.com

Mérida, Venezuela

\section{Resumen}

El presente ensayo, de carácter documental, tiene como propósito, hacer un enfoque de la transdisciplinariedad en la educación universitaria como proceso que facilita la superación de la perspectiva fragmentaria que presenta la manera de enseñar y aprender en la universidad. En este estudio se considera de igual importancia, abordar los conceptos de disciplinariedad, interdisciplinariedad, multidisciplinariedad y pluridisciplinariedad como preámbulo al concepto de transdisciplinariedad, a los fines de clarificar estos puntos y contar con una mejor percepción del tema tratado. Se considera, que la transdisciplinariedad es el proceso que promueve el surgimiento de nuevos campos del conocimiento a partir del diálogo de disciplinas. Es relevante considerar que el acercamiento a la transdisciplinariedad conlleva escenarios críticos en el campus universitario en los que docentes y estudiantes puedan actuar libremente para expresar su cuestionamiento a los paradigmas educativos de la actualidad.

Palabras clave: enseñanza superior; conocimiento; disciplina. 


\section{Transdisciplinarity: A Look at University Education}

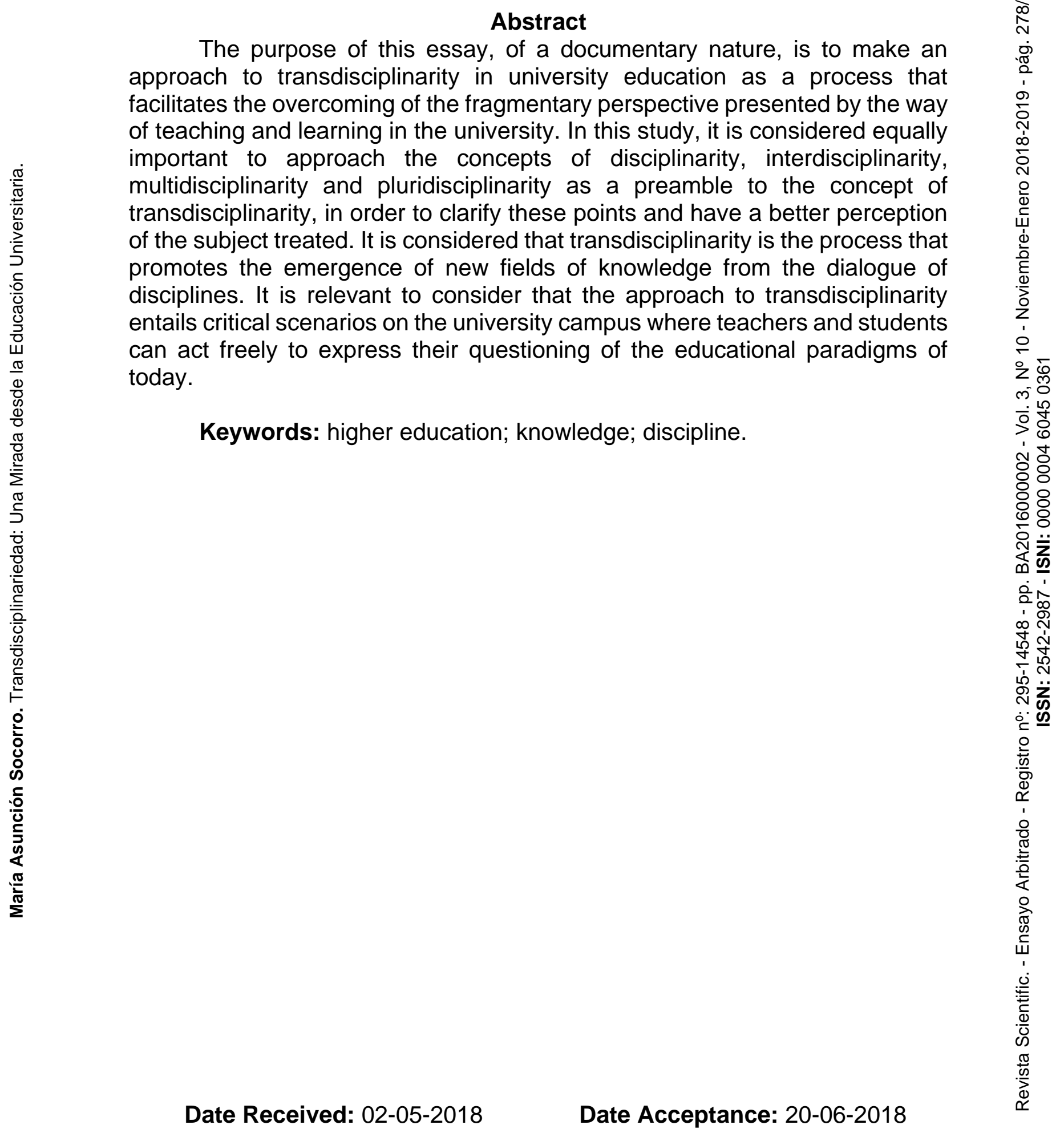




\section{Introducción}

Previo a dar inicio a los planteamientos de la transdisciplinariedad en el área de la educación universitaria, es relevante analizar y reflexionar sobre las definiciones de disciplina, interdisciplina, multidisciplina, transdisciplina, su importancia, en el marco de globalización y la sociedad del conocimiento.

Para Morin (1992:7): la disciplina es una categoría de organización del conocimiento científico, pues se encarga de la división y la especialización del trabajo, además de dar respuesta a la diversidad de los dominios que arropan la ciencia. Este autor agrega que la especialidad está comprendida por medio de un conjunto científico más extenso, tiende por naturaleza hacia la emancipación, la clarificación de sus fronteras, el lenguaje que la conforman, las técnicas que debe construir o emplear, y esporádicamente por las teorías que se vinculan a ella.

Como disciplina el ordenamiento del conocimiento se institucionalizó durante el siglo XIX, específicamente con la creación de universidades que luego se transformaron en las actuales instituciones de educación superior. Luego, en el siglo XX se amplió con el apoyo e impulso a la investigación científica; lo que indica que cada disciplina posee su propia historia: génesis, institucionalización, evolución, difusión y divulgación del conocimiento en cada una de ellas, entre otros aspectos.

Su desarrollo histórico se enmarca en la universidad que a su vez está contenida en el devenir histórico de la sociedad, por ende, las disciplinas se originan en el contexto de la sociología de las ciencias y de la sociología del conocimiento, además de un proceso de análisis reflexivo interno sobre ella misma, así como de un saber exterior; de allí que no es suficiente hallarse en el interior de una de ellas para percibir y estar al tanto de toda la problemática inherente a ella.

Por su parte, Ugas (2006a:89): señala que las disciplinas en sentido estricto, "se justifican siempre que guarden un campo de visión que reconozca 
y conciba la existencia de vínculos de solidaridad y no oculten la existencia de relaciones globales".

\section{Concepción de la inter, multi y transdisciplinariedad}

La interdisciplinariedad se puede definir, según Borrero (2008a:671): como "la innata relación de ciencias, profesiones y especialidades, en procura de alguna forma de unidad de las ciencias, de currículos que concierten los diferentes dominios de las mismas y los conocimientos humanos y de soluciones adecuadas a los complejos problemas de la sociedad".

En este contexto es relevante considerar que a través de la interdisciplinariedad se pretende formar personas omnicomprensivas del escenario plurifacético de las ciencias y los conocimientos, con la visión de superar el sectarismo de las profesiones. Esta relación entre distintas disciplinas del conocimiento considera el escenario actual de las especialidades, sometidas a continuas transformaciones de su identidad, forzados por las relaciones requeridas con otros campos profesionales.

Por otra parte, la interdisciplinariedad desde un punto de vista conceptual puede ser considerada como una forma de cooperación entre distintas disciplinas que aportan al logro de un fin común y que, por medio de su asociación, auspician el surgimiento y el desarrollo de un nuevo conocimiento. Nicolescu (1996a:168): la concibe de la manera siguiente: "la interdisciplinariedad ha sido definida de manera muy variada [...] como una metodología, un concepto, un proceso, una manera de pensar, una filosofía y una ideología reflexiva", agregando que se ha relacionado con los esfuerzos de exponer los riesgos de la fragmentación, de restablecer viejas conexiones, de explorar relaciones insurgentes, y de formar nuevos sujetos adecuados para responder a necesidades prácticas y conceptuales.

Gibbons, Limoges, Nowotny, Schwartman, Scott y Trow (1997:44): sostienen que la interdisciplina se caracteriza por la formulación explícita de 
una terminología estándar, que trasciende la norma, o por una metodología coincidente. La formación que adopta el trabajo común de la ciencia se basa en trabajar sobre diversos temas, pero en el marco de una estructura común que es compartida por todas las disciplinas involucradas.

Para Ugas (2006b:90): "la interdisciplinariedad concierne a la transferencia de métodos de una disciplina a otra”. En este sentido, el autor señalado agrega que para esta transferencia interdisciplinaria de métodos se diferencian tres niveles: el primero está relacionado con su aplicación, el segundo con la epistemología y, el tercero, se vincula con la concepción de nuevas disciplinas. Este criterio reafirma lo señalado por los autores mencionados con anterioridad, pues es necesaria la cooperación y el trabajo conjunto entre varias disciplinas para encontrar respuestas a una situación en particular, por lo que los tres niveles se convierten así, en bases fundamentales para que la interdisciplinariedad se haga patente.

Sin embargo, el autor mencionado, a pesar de concibe la interdisciplinariedad con claridad, no hace lo mismo con el concepto de multidisciplinariedad, por lo que se considera que es relevante hacerlo por su importancia en el desarrollo de la enseñanza y el aprendizaje. En tal sentido, la multidisciplinariedad se refiere a las disímiles disciplinas, al fraccionamiento de las áreas científicas, al progreso de las ramificaciones del conocimiento, a lo más puntual del avance científico y tecnológico, así como a la ampliación de conocimientos. Para afrontar cualquier área determinada de la realidad participan múltiples disciplinas que convergen en su resolución, de allí que la multidisciplinariedad informa sobre las disciplinas, ciencias o ramas del conocimiento que están relacionadas y hacen aportes cognitivos sobre lo concreto de un problema.

Para Martínez (2013a:90): "en la investigación multidisciplinaria trabajan diferentes investigadores colaborando en un proyecto común. Los participantes pertenecen a diversas disciplinas y cada uno es básicamente 
independiente en su trabajo, sintiendo poca o ninguna necesidad de conocer el trabajo de los demás". Lo explicado por este autor se pone de manifiesto en el ejemplo siguiente: con el propósito de que los estudiantes cuenten con material de apoyo para las evaluaciones finales de las asignaturas, los docentes preparan guías de ejercicios. Eso sí, cada uno de ellos, elabora el material correspondiente a la disciplina a la que pertenece, sin interesarse por el material que han elaborado el resto de los docentes.

Para definir la transdisciplinariedad, Ugas (2006c:90): señala que "consiste en el estudio del objeto de una sola y misma disciplina por medio de varias disciplinas a la vez", mientras que Nicolescu (1996b:41): la considera como "el estudio del objeto de una sola y misma disciplina por medio de varias disciplinas a la vez", mientras que para Borrero (2008b:24): significa mantener la simple relación, la yuxtaposición y el paralelismo no articulado de las disciplinas, pues hay una al menos que actúa sobre las otras como eje de rotación.

De acuerdo con los conceptos aportados por los autores que se han mencionado para la definición de multidisciplinariedad y pluridisciplinariedad, la primera se refiere a la organización de contenidos de una forma más tradicional. Por ejemplo, los contenidos escolares se presentan por asignaturas no dependientes entre sí. El conjunto de disciplinas se propone paralelamente sin que lleguen a manifestarse explícitamente las relaciones que puedan surgir entre las materias involucradas. Esa organización de carácter sumativa es la que prevalece en la educación media e inclusivo en al superior.

En cuanto a la pluridisciplinariedad, el término hace referencia a la existencia de relaciones complementarias entre disciplinas con cierta afinidad. Este hecho se pone de manifiesto en las aportaciones mutuas de las distintas historias, por ejemplo: de la ciencia, la física, la química, las matemáticas, la biología, el arte, entre otras, o de las distintas disciplinas de las ciencias 
experimentales. La constitución de los variados departamentos, dependencias o instancias de educación media e incluso, de la superior, es un ejemplo de pluridisciplinariedad.

Por otra parte, al considerar los fundamentados de los conocimientos disciplinarios, interdisciplinarios, multidisciplinarios, pluridisciplinarios, es de relevancia hacer referencia al criterio de Ugas (2006d:90): con respecto a la transdisciplinariedad, afirma que esta "concierne, como lo indica el prefijo 'trans', a lo que simultáneamente es entre las disciplinas a través de las diferentes disciplinas y más allá de toda disciplina". Agrega el mencionado autor que su propósito se basa en el entendimiento del mundo contemporáneo, siendo uno de sus requisitos más relevantes el conocimiento en un todo.

Por lo tanto, la transdisciplinariedad se puede comprender como algo que se encuentra simultáneamente entre las disciplinas, por medio de las distintas especialidades de la ciencia, sobrepasando los límites de otros campos del conocimiento, surgida para dar respuesta al requerimiento de bregar con los retos permanentes de los problemas que afectan al mundo actual y que exigen un tratamiento multi-referencial debido a su naturaleza compleja.

\subsection{La transdisciplinariedad en el contexto de la educación universitaria}

La educación universitaria y la transdisciplinariedad, sin lugar a duda, se encuentran entrelazadas ente sí por su importancia en la formación de especialistas y en el diseño de las disciplinas, además los conocimientos transdisciplinarios no se adquieren automáticamente como resultado único del avance de la ciencia y la tecnología, sino que requiere de una tarea profunda, consciente y orientada a esta meta.

De acuerdo con Morin (2011a:141):

En la medida en que son mal percibidas, infravaloradas y separadas unas de otras, todas las crisis de la humanidad 
planetaria son, al mismo tiempo, crisis cognitivas. Nuestro sistema de conocimientos, tal y como se nos inculca y fija en la mente, conduce a importantes conocimientos.

Así mismo agrega Morin que el modo de conocimiento de los seres humanos no ha trabajado con suficiencia la capacidad para contextualizar la información, de manera que pueda ser integrada en un todo que le proporcione entendimiento.

Como individuos, afirma Morin (2011b:141), lo siguiente:

sumergirnos en la sobreabundancia de informaciones, cada vez nos es más difícil contextualizarla, organizarla y comprenderla. La fragmentación y la compartimentación del conocimiento en disciplinas que no se comunican nos impiden percibir y concebir los problemas fundamentales y globales. La hiperespecialización rompe el tejido complejo de lo real, el predominio de lo cuantificable oculta las realidades afectivas de los seres humanos.

En este contexto, siguiendo las palabras de Morin, surge la transdisciplinariedad que Martínez (2013b:86): la relaciona con un conocimiento superior emergente, producto de una tendencia dialéctica que se nutre del pensamiento, permitiendo superar los límites de los distintos campos del conocimiento disciplinar, con el propósito de generar imágenes más completas de la realidad, mejor integradas, por tanto, más verdaderas.

Se trata, de acuerdo con lo planteado por el autor señalado, el propósito se enfoca dar soluciones al parcelamiento y la fragmentación del conocimiento que proyectan las disciplinas particulares y su derivada hiperespecialización, de allí su incapacidad para comprender las complejas realidades del mundo actual, distinguidas por el conjunto de nexos, relaciones e interconexiones de los elementos que la constituyen.

A partir del siglo XIX, el sistema educativo $y$, en particular el universitario, casi en su totalidad, se ha representado por su carácter 
disciplinario y por organizar e impartir el conocimiento fragmentadamente, asociando el saber dentro de los currículos en unidades separadas, sin que se establezcan relaciones entre unas y otras, como elementos dispersos de un rompecabezas que se suministran a los estudiantes, sin indicarles las instrucciones para su armado. Ello genera, en los alumnos, dificultades para comprender y vincular los conocimientos entre sí, incapacidad para trasladar las aplicaciones de un área del saber a otra, imposibilidad de calibrar los conocimientos para usar el más idóneo en un caso concreto, y la percepción de que el conocimiento aprendido de manera fragmentada carece de sentido, pues no corresponde a la realidad por abordar.

Este hecho no se presenta gratis, se trata de la proyección, en el campus universitario, de la manera en que se organiza y se produce el conocimiento científico, cuyos resultados constituyen los contenidos de la educación superior en el mundo contemporáneo: la disciplinariedad, que se caracteriza por su atomización del conocimiento y se basa en el paradigma positivista clásico de la ciencia. En otras palabras, el paradigma divisionista del conocimiento llega a ser asumido por las universidades, conllevando un modelo educativo bajo iguales características.

\section{Conclusiones}

El acercamiento a la transdisciplinariedad genera en el campus universitario un escenario crítico desde el cual docentes y estudiantes puedan sentirse libres, para cuestionar y expresar su desapego hacia los paradigmas educativos actuales, por lo que es relevante resaltar que se ha presentado una transformación evolutiva en el proceso de enseñanza y aprendizaje, el cual debe ser enfocado desde el aprender haciendo, aprender y desaprender, a vivir en colectividad, pues sólo así es que los seres humanos generan conocimiento que puede conducir, a través de la educación, hacia una amplitud de saberes que no puede estar limitada a un entorno de vida. 
En tal sentido, una educación universitaria auténtica, integral desde el punto de vista de la transdisciplinariedad, no tiene por qué favorecer el enajenamiento del conocimiento; por el contrario, su propósito debe centrarse en la contextualización, la concreción y la globalización de los saberes compartidos. La educación transdisciplinaria le aporta nuevos valores al papel que deben desempeñar las universidades, así como al imaginario y a la transmisión del conocimiento. Por consiguiente, la educación transdisciplinaria no sólo debe ser desarrollada en la universidad, sino que su aplicación debe iniciarse en la educación maternal hasta la educación superior, al igual que en todos los ámbitos de la vida.

De allí que desde la academia se debe reflexionar para presentar planificaciones relacionadas con la apertura de la educación superior, inclinando la balanza hacia el deber ser y el ser de las universidades venezolanas, particularmente de las universidades politécnicas territoriales, con el propósito de formar profesionales integrales con perfiles inter 0 transdisciplinarios, capaces de enfrentar la realidad y aportar respuestas viables y confiables a una sociedad que las requiere.

\section{Referencias}

Borrero, A. (2008a,b). La Universidad. Estudios sobre sus orígenes, dinámicas y tendencias. Bogotá, Colombia: Editorial Pontificia Universidad Javeriana.

Gibbons, M., Limoges, C., Nowotny, H., Schartzman, P., Scott, P., \& Trow, M. (1997). La nueva producción del conocimiento. Barcelona, España: Pomares-Corredor.

Martínez, M. (2013a,b). Epistemología y metodología cualitativa en las ciencias sociales. México: Trillas.

Morin, E. (1992). Sobre la interdisciplinariedad. ICESI, (62). Colombia: Trabajo presentado en Medellín, en el curso internacional sobre La 
complejidad y la transdisciplinariedad, organizado por la Dirección de Investigaciones de la U.P.B., Unesco, Colciencias, CNRS, Embajada Francesa y Unisalle, págs. 9-15. Recuperado de:

https://www.icesi.edu.co/revistas/index.php/publicaciones icesi/article /view/643

Morin, E. (2011a,b). La Vía. Para el futuro de la humanidad. Barcelona, España: Editorial Paidós, Estado y Sociedad.

Nicolescu, B. (1996a,b). La Transdisciplinariedad. Manifiesto. Éditions du Rocher. Collection Transdisciplinarité. México: Multiversidad Mundo Real Edgar Morin.

Ugas, G. (2006a,b,c,d). La complejidad: un modo de pensar. San Cristóbal, Venezuela: Taller permanente de Estudios Epistemológicos en Ciencias Sociales. 


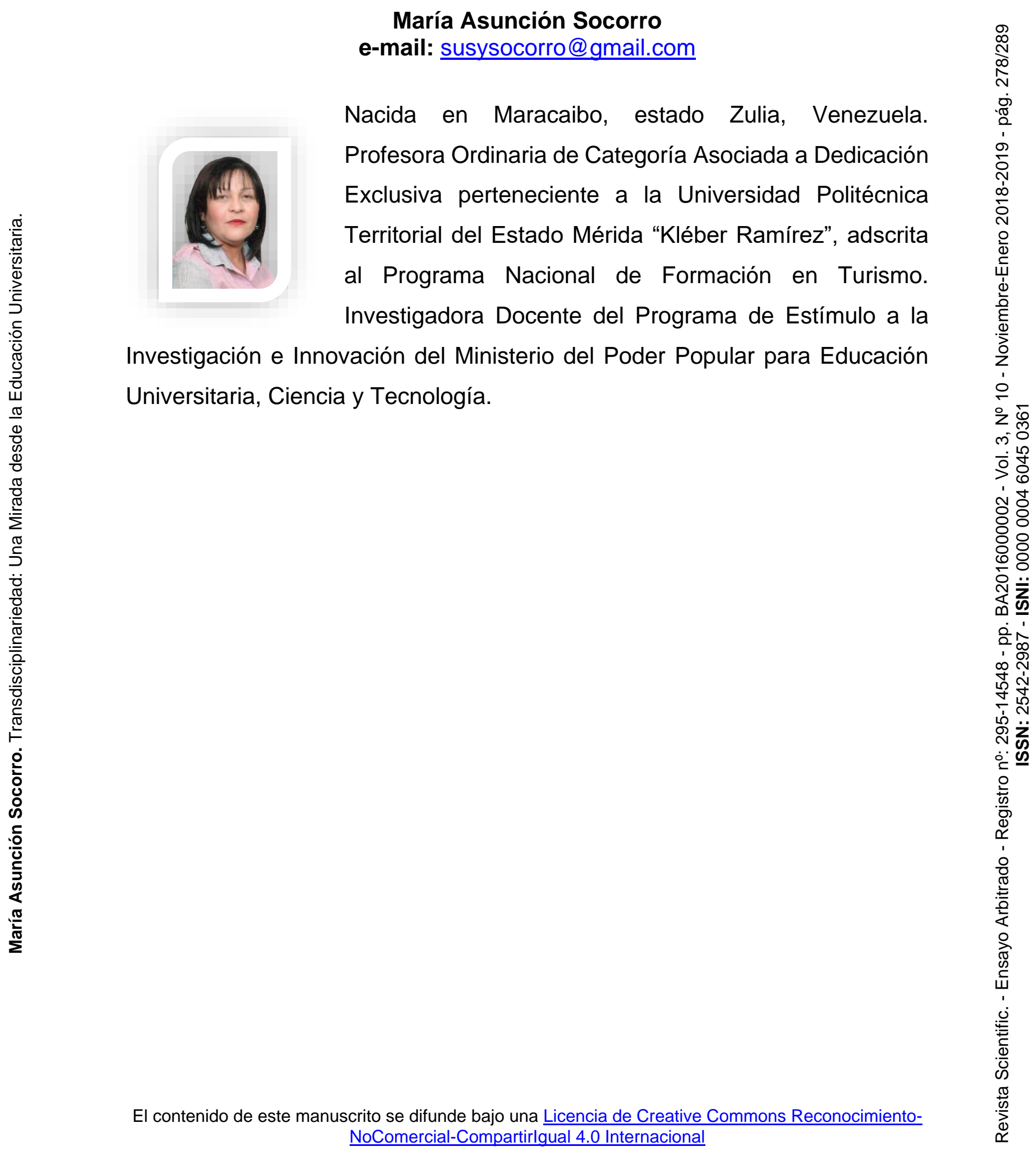

